\title{
Letters
}

Website: www.bmj.com

Email: letters@bmj.com

\section{Genetically modified foods and the Pusztai affair}

EDITOR-In his clinical review on genetically modified foods Jones implies that Pusztai had tested only the effects of potato spiked with concanavalin A (a lectin) at the Rowett Institute. ${ }^{1}$ The initial dissemination of this incorrect information followed by the inappropriate suspension of Pusztai and the suspicion of fraud implied by instituting an audit according to Medical Research Council guidelines led some scientists, including me, to defend Pusztai, whom we know to be an honourable and careful scientist. The report of the audit conducted at the Rowett Institute (www.rri.sari.ac.uk/ press) clearly shows that experiments on transgenic potatoes containing the gene for the snowdrop lectin (GNA) had already been performed when Pusztai was interviewed for World in Action in August 1998. If the Rowett Institute had released a statement that the work was preliminary and allowed the work to continue such a potentially damaging media storm would probably not have happened.

Not all lectins are toxic. They are ubiquitous carbohydrate binding proteins. All mammalian cells and blood and all plant nuts, seeds, and bulbs, including many

\section{Advice to authors \\ We prefer to receive all responses electronically, sent either directly to our website or to the editorial office as email or on a disk. Processing your letter will be delayed unless it arrives in an electronic form. \\ We are now posting all direct submissions to our website within 72 hours of receipt and our intention is to post all other electronic submissions there as well. All responses will be eligible for publication in the paper journal. \\ Responses should be under 400 words and relate to articles published in the preceding month. They should include $\leqslant 5$ references, in the Vancouver style, including one to the BMJ article to which they relate. We welcome illustrations. \\ Please supply each author's current appointment and full address, and a phone or fax number or email address for the corresponding author. We ask authors to declare any competing interest. Please send a stamped addressed envelope if you would like to know whether your letter has been accepted or rejected. \\ Letters will be edited and may be shortened. \\ www.bmj.com \\ letters@bmj.com} cooked before ingestion. development. potato or its promoter. rhodesjm@liverpool.ac.uk

non-toxic food components, contain lectins. ${ }^{2}$ Some of these, in red kidney beans for example, are toxic and need to be destroyed by heat before consumption, ${ }^{3}$ but others such as tomato lectin are apparently harmless when eaten raw. Many plant lectins have an insecticidal or antifungal role in the plant. Some of these food lectins have interesting biological effects. We have recently shown that the common edible mushroom lectin that is often eaten raw selectively inhibits nuclear protein import. The snowdrop lectin (GNA) binds to mannose, which is minimally expressed in mammalian intestine but extensively expressed in the intestine of sap sucking insects. Thus expression of this lectin in food plants might render them unattractive to insects but safe for human consumption, particularly if the food (potato) is always

Pusztai's experiments, whatever their results, would not show that all genetically modified foods were unsafe. Pusztai's message was simply that such foods require careful testing. As with the testing of new pharmaceutical agents, some transgenic foods will prove toxic or otherwise unsatisfactory and be discarded at an early stage of

The fact that Pusztai has been barred from continuing his experiments since the time of his initial suspension has meant that his data remain preliminary, and further experimentation will probably be needed before any final conclusions can be drawn about the effects of the transgenic GNA

There has been little clarity surrounding this debate, and one lesson that needs to be learnt is that all scientists need to be careful to ensure that their comments inform rather than confuse when handling issues that are of such extreme public interest.

Jonathan M Rhodes Professor of medicine University of Liverpool, Liverpool L69 3GA

1 Jones L. Genetically modified foods. BMJ 1999;318:581-4

(27 February.)
2 Rhodes JM. Beans means lectins. Gut 1999;44:593-4.

3 Freed DW. Do dietary lectins cause disease? BMJ 1999;318:1023-4. (17 April.)

4 Yu L-G, Fernig DG, White MRH, Spiller DG, Appleton P, Evans RC, et al. Edible mushroom (Agaricus bisporus) lectin, which reversibly inhibits epithelial cell proliferation, blocks nuclear localization sequence-dependent nuclear protein import.J Biol Chem 1999;274:4890-9.

\section{Vitamin D deficiency}

Time for a tablet containing high doses of vitamin $D$ alone

EDITOR-I was heartened to read Compston's editorial calling for action on vitamin D deficiency. ${ }^{1}$ Another point should be made to encourage a more active role by the health service.

The British National Formulary does not include a tablet containing vitamin $\mathrm{D}$ alone in reasonable dose. Prescribers can give a calcium and vitamin D mixture, which may be unpalatable and therefore impair compliance. Alternatively, a vitamin capsule can be prescribed containing many other vitamins. If a dose greater than minimal daily requirements is needed higher doses of unnecessary vitamins must also be given. Surely it should be easy to prescribe 500-1000 units of vitamin D daily without any other addition?

C $\mathbf{H}$ Cheetham Consultant paediatrician

Wycombe General Hospital, High Wycombe, Buckinghamshire HP11 2TT

lesley.martyn@wyclib.demon.co.uk

1 Compston JE. Vitamin D deficiency: time for action. BMJ 1998;317:1466-7. (28 November.)

\section{Groups at risk need supplementation, and milk could be fortified}

EDITOR-We agree with Compston that the time has come for reappraisal of measures aimed at preventing vitamin $\mathrm{D}$ deficiency with consequent bone loss predisposing to osteoporotic fracture. ${ }^{1}$ The high prevalence of vitamin D deficiency and secondary hyperparathyroidism with high bone turnover emphasises this urgent need.

The adequacy of current vitamin D intake recommendations is being questioned. The most sensitive yardstick for ascertaining the degree of hypovitaminosis $\mathrm{D}$ that predisposes to bone disease is secondary hyperparathyroidism. Vitamin D deficiency is known to occur even at a serum 25-hydroxyvitamin D concentration previously considered adequate-namely, $37.5 \mathrm{nmol} / \mathrm{l}$. Over the past two years the threshold has been found to exceed $75 \mathrm{nmol} / 1$ in both middle aged ${ }^{2}$ and elderly ${ }^{3}$ people irrespective of calcium intake. Calcium intake can modulate parathyroid function and bone resorption even in subjects who are replete with vitamin $\mathrm{D}^{3}$ While the outcome of studies comparing the effectiveness of supplementation with low dose vitamin $\mathrm{D}$ with or without calcium in reducing the incidence of bone fracture is awaited, two courses of action are required. 
The first is supplementing groups at risk with vitamin D (400-800 IU/day) and calcium $(500-1000 \mathrm{mg} /$ day), which is safe and effective. The second is fortifying milk as a public health measure to benefit both young ${ }^{4}$ and old $^{5}$ people.

Rosemarie Freaney Principal biochemist Malachi J McKenna Consultant endocrinologist Metabolism Laboratory, St Vincents Hospital, Dublin 4, Republic of Ireland

1 Compston JE. Vitamin D deficiency: time for action. BMJ 1998;317:1466-7. (28 November.)

2 Chapuy MC, Preziosi P, Maamer M, Arnaud S, Galen P, Hercberg S, et al. Prevalence of vitamin D deficiency in an adult normal population. Osteoporos Int 1997;7:439-43.

3 McKenna M, Freaney R. Secondary hyperparathyroidism in the elderly: means to defining hypovitaminosis $\mathrm{D}$. Osteoporos Int 1997;8(suppl 2):S3-6.

4 McKenna M, Freaney R, Byrne P, McBrinn Y, Murray B, Kelly M, et al. Safety and efficacy of increasing wintertime vitamin $\mathrm{D}$ and calcium intake by milk fortification. $Q J M e d$ vitamin D and cal

5 Keane EM, Healy M, O'Moore R, Coakley D, Walsh JB. Vitamin D-fortified liquid milk: benefits for the elderly community-based population. Calcif Tiss Int 1998;62 $300-2$

\section{Guidelines are needed for treating} diseases of bone metabolism in epilepsy

EDITOR-Compston's editorial is a timely reminder that hypovitaminosis $\mathrm{D}$ is a common neglected problem in susceptible populations, with adverse effects on bone mass and increased fracture risk.

The editorial, however, raises as many questions as it answers. Although acknowledging uncertainty over the best dose of and route of administration for vitamin $\mathrm{D}$ and whether it should be given with calcium, Compston suggests that routine supplementation (800 IU or $20 \mu \mathrm{g}$ daily) should now be given to elderly people and other high risk populations. In epilepsy the risk of bony injury is increased because of the seizures, and the use of antiepileptic drugs is also associated with disorders of bone metabolism resulting in osteopenia and, occasionally, osteomalacia. This is attributed to vitamin $\mathrm{D}$ deficiency as a consequence of enzyme induction and increased vitamin D catabolism, although antiepileptic drugs have additional direct effects on bone metabolism. ${ }^{2}$ Changes seem to be influenced by sex, duration of treatment, whether the drug is given alone or with others, and whether the drug is enzyme inducing. Although Compston includes patients with epilepsy among those at risk, it is not clear whether all patients taking antiepileptic drugs or only specific groups should receive supplementation. Is the dose recommended intended as prophylaxis in patients starting treatment or to correct established bone disease, in which hypovitaminosis requires far higher doses of vitamin $\mathrm{D} ?^{3}$ When should bone metabolism or density, or both, be assessed before supplementation, and how should treatment be monitored? Is supplementation required in patients receiving new antiepileptic drugs? And, given that epilepsy is common in children when maximum bone accretion occurs, how early in life should supplementation start?

Some 400000 people in the United Kingdom have epilepsy, most of whom are taking antiepileptic drugs without supplementation. Blanket prescribing of vitamin D has economic consequences. Supplementation may unmask undiagnosed primary hyperparathyroidism. Furthermore, a distinction needs to be made between recommendations on prophylaxis in patients starting treatment with antiepileptic drugs and the identification and treatment of osteopenia and osteomalacia in patients already receiving long term treatment, especially in the presence of other risk factors.

Lina Nashef Consultant neurologist

lina.n@virgin.net

Edmund Lamb Consultant clinical biochemist Kent and Canterbury Hospital, Canterbury CT1 3NG

\section{Compston JE. Vitamin D deficiency: time for action. $B M J$ 1998:317:1466-7. (28 November) \\ 2 Valimaki MJ, Tiihonen M, Latinen K, Tahtela R, Karkkaine M, Lamberg-Allardt C, et al. Bone mineral density measured by dual-energy $\mathrm{x}$-ray absorptiometry and novel markers of bone formation and resorption in patients on antiepileptic drugs.J Bome Min Res 1994;9:631-7. \\ 3 Collins N, Maher J, Cole M, Baker M, Callaghan N. A pro- spective study to evaluate the dose of vitamin $\mathrm{D}$ required to correct low 25-hydroxyvitamin D levels, calcium, and alka- line phosphatase in patients at risk of developing anti- epileptic drug-induced osteomalacia. Q J Med 1991;78} $113-22$

\section{Author's reply}

EDITOR-Cheetham correctly points out the inadequacy of the dose of vitamin D contained in current formulations. It is also true that preparations containing calcium and vitamin $\mathrm{D}$ may be less well tolerated. However, the studies showing reduced nonvertebral fracture risk in elderly people used both calcium and vitamin $\mathrm{D},{ }^{1}$ and whether vitamin $\mathrm{D}$ alone is effective remains to be established. Although higher dose vitamin D tablets would be useful in some clinical situations, concurrent calcium supplementation may be required for protection against fractures in elderly people.

Freaney and McKenna raise the central issue of defining hypovitaminosis $\mathrm{D}$. As they state, the current threshold may be too low and potential beneficiaries of vitamin $\mathrm{D}$ supplementation may include those who were previously believed to be replete with vitamin D. In addition to supplementation of groups at risk, fortification of milk would be a step forward, but experience in the United States and Canada has shown wide variations in the vitamin D content of fortified milk so the benefits of this approach would be limited to those who drink sufficient quantities of milk. ${ }^{2}$

Nashef and Lamb raise several questions. Anticonvulsant treatment is a risk factor for osteomalacia and osteoporosis and is associated with an increased prevalence of hypovitaminosis $\mathrm{D}$. The amount of vitamin $\mathrm{D}$ required to achieve normal serum 25-hydroxyvitamin D concentrations in patients receiving anticonvulsants varies, in one study ranging between $400 \mathrm{IU}$ and 4000 IU daily. ${ }^{3}$ The use of enzyme inducing drugs, particularly in high doses and with other drugs, and lack of exposure to sunlight as a result of being housebound or living in an institution are major risk factors for hypovitaminosis D. A strong case can be made for routine supplementation in such subjects, with serum 25-hydroxyvitamin D concentrations being measured to monitor treatment. There is no reason why children should not be supplemented with vitamin $\mathrm{D}$, although the dose may require adjustment. For other subjects at lower risk serum 25-hydroxyvitamin D concentrations should be determined to assess the need for supplementation; this should probably include patients taking the newer anticonvulsants since little is known about their effects on vitamin D status. Even the higher doses of vitamin $\mathrm{D}$ required for patients receiving anticonvulsant treatment are safe, and the benefits of preventing hypovitaminosis $\mathrm{D}$ are likely to far outweigh rare events such as the unmasking of primary hyperparathyroidism.

J E Compston University lecture

Department of Medicine, Addenbrooke's Hospital, Cambridge CB2 2QQ

1 Chapuy MC, Arlot ME, Delmas PD, Meunier PJ. Effect of cholecalciferol treatment for three years on hip fracture in elderly women. BMJ 1994;306:1081-2.

2 Dawson-Hughes B, Harris SS, Krall EA, Dallal GE. Effect of calcium and vitamin D supplementation on bone density in men and women 65 years of age or older. $N$ Engl J Med 1997;337:670-6.

3 Collins N, Maher J, Cole M, Baker M, Callaghan N. A prospective study to evaluate the dose of vitamin $\mathrm{D}$ required to correct low 25-hydroxyvitamin D levels, calcium, and alkaline phosphatase in patients at risk of developing akleptic drug induced osteomalacia. O J Med 1991;78:113-22.

\section{Medical rules are needed in marathons in the United Kingdom}

EDITOR-Dyer reports that two junior doctors, Andrew Murphy and Lesley McKee, went to the aid of a marathon runner who collapsed and died as she crossed the finishing line of a half marathon. ${ }^{1}$ Dyer reports Dr Murphy as saying that if he was faced with a similar emergency in future he would "just walk on by." We understand his comments.

It should not have been necessary for a doctor who had just finished a gruelling half marathon to take part in a resuscitation attempt. Emergency medical assistance should remain the responsibility of race organisers and those hired to provide emergency medical care. Our daughter collapsed at a public event where competitors had paid for medical assistance in their entrance fee. The organisers should have employed a doctor qualified to deal with such an emergency, especially as another young person had died at the finish line in the previous year's event.

If everything had been done correctly to save Anna that would have been the end of the matter. The absolute tragedy of Anna's death is that she collapsed at the finish line close to St John Ambulance staff with a modern automatic external defibrillator, which could have quickly provided the defibrillating shock she needed to survive.

Evidence given at the inquest showed that, although the staff reached her within less than a minute, they did not diagnose 
cardiac arrest or follow the correct defibrillator procedures. The first seven minutes of the resuscitation attempt is well documented by the internal defibrillator electrocardiograph and audiotape recording, which showed continuous ventricular fibrillation, but no shock was given despite the machine's prompting the operator to do so.

UK Athletics 98 rules require only that there be a qualified medical officer and an emergency medical centre to cope with two emergencies per 1000 people at the finish. There is no information on the degree or quality of care required. Neither do they specify the need for advanced life support or advanced cardiac life support, the role of medical staff, or what is meant by emergency.

In France, medical rules are comprehensive and legally binding. They call for a high degree of mobility of a doctor skilled in resuscitation, paramedical ambulances, and an effective means of radio communication. Since their introduction in 1992 only eight people have died in out of stadium running events throughout France.

A campaign was launched on $8 \mathrm{March}$, the anniversary of Anna's death, requiring the sports minister to compel organisers to provide advanced life support at these strenuous events. It is backed by Don Foster, MP for Bath, and we welcome support from the medical profession. The current haphazard system which puts bystander doctors in such a difficult position should not be allowed to continue.

Some 70 athletes have died in the past 10 years in the United Kingdom at these events. Information on them is being compiled by Rob Perkins (email: rob@ newsquick.co.uk; tel 0121684 3222; fax: 0121684 3224). Please contact him if you have any information or would like more details of the campaign.

Phillip Loyley Father of Anna Loyle

Pauline Loyley Mother of Anna Loyley

Bath BA2 2EE

loyley.int@dial.pipex.com

1 Dyer C. “Good Samaritans" face grilling. BMJ 1998;317: 1100. (24 October.)

\section{Pseudo-EBM-ers have their own lexicon}

EDITOR-Molesworth is to be commended for drawing our attention to the clear differences between those who are EBM-ers and those who are not. ${ }^{1}$ But, alas, life is never that simple. He has failed to acquaint his readers with a pernicious class of practitioners known to students of the field as pseudoEBM-ers. These wily folk are not easily identified by appearance or position. However, if listened to carefully-often a taxing experience-their speech is virtually pathognomonic. I provide here a few key phrases with their translations to assist the uninitiated in distinguishing real from pseudo-EBM:

- "The literature suggests" = I haven't actually read anything, but, if I had, I bet it would say...
- "The last paper I read on the subject" = a dimly recalled reference from a dozen years ago

- "Their results may be statistically significant, but they lack clinical relevance" $=\mathrm{I}$ disagree with their findings

- "Existing evidence is as yet too insubstantial to permit definitive conclusions" = I haven't a clue what you're on about.

Sam Shortt Director, Queen's health policy

Queen's University, Kingston, Canada

shortt@qhp.queensu.c 1 Molesworth N. Down with EBM. BMJ 1998;317:1720-1.
(19-26 December.)

\section{Pregnancy does not mean that patients with tuberculosis must stop treatment}

EDITOR-We were disappointed that Rubin's review of drugs that could safely be taken in pregnancy did not mention drugs for tuberculosis. ${ }^{1}$ Adherence to successful treatment of tuberculosis is essential. In 1998 three patients with tuberculosis (of 114 such patients treated at Homerton Hospital) became pregnant; all three were advised by their general practitioner or midwife to stop their treatment, and two accepted a termination. In addition, two of 71 female patients receiving preventive treatment with isoniazid were advised to stop treatment after a pregnancy test gave a positive result

The British Thoracic Society's guidelines state: "None of the first line drugs has been shown to be teratogenic. . . . Streptomycin should be avoided as [it] may be ototoxic." In the United States caution is expressed regarding the use of pyrazinamide, but data do not indicate any adverse effects. ${ }^{3}$ Hamedeh and Glassroth reviewed the literature concerning over 2000 pregnancies in mothers with tuberculosis and found no significant difference in side effects in these women compared with non-pregnant subjects and no higher incidence of fetal abnormalities; they commented that "there is no indication for the interruption of pregnancy" for those with tuberculosis and that "untreated tuberculosis represents a far greater hazard to a pregnant woman and her fetus than does treatment of the disease."

Theoretical considerations suggest that the immune response in pregnancy, which shifts $\mathrm{T}$ cell responses away from cell mediated immunity (Th1) and towards antibody help (Th2), could allow tuberculosis to develop in those who have been infected with the tubercle bacillus. The greater proportion of pregnant patients with smear positive pulmonary tuberculosis is in keeping with this hypothesis (usually this form of the disease is more common in men $)^{4}$; active disease should arise in infected pregnant women more commonly than in others with a positive tuberculin response. Concerns have been raised about the incidence of hepatitis induced by isoniazid during pregnancy, ${ }^{5}$ although the women may have had concurrent viral hepatitis and differences have not been significant.

The incidence of hepatitis due to isoniazid increases with age over 35 . On these grounds it seems reasonable to complete preventive treatment that has been started but to delay treatment with isoniazid until after delivery in those in whom a tuberculin skin test gives a positive result. Treatment should not, however, be withheld from patients with active disease, nor termination advised.

Graham Bothamley Consultant respiratory physician Will Elston Specialist registrar

East London Tuberculosis Service, Homerton Hospital, London E9 6SR

1 Rubin P. Drug treatment during pregnancy. BMJ 1998;317:1503-5. (28 November.)

2 Joint Tuberculosis Committee of the British Thoracic Society. Chemotherapy and management of tuberculosis in the United Kingdom: recommendations 1998. Thorax 1998;53:536-48.

3 Brost BC, Newman RB. The maternal and fetal effects of tuberculosis therapy. Obstet Gynecol Clin N Am 1997;24: $659-73$

4 Hamadeh MA, Glassroth J. Tuberculosis and pregnancy. Chest 1992;101:1114-20.

5 Moulding TS, Bedeker AG, Kanal GC. Twenty isoniazid-

associated deaths in one state. Am Rev Respir Dis 1989;140: $700-5$

\section{Cluster randomised trials}

\section{Standardised approach to analysing and} reporting these trials is misguided

EDITOR-In their editorial on cluster randomised trials Campbell and Grimshaw correctly identify the importance of the appropriate choice of the unit of analysis. Unfortunately, they display a disappointingly poor grasp of the basis of estimation, and the specific recommendations that they make are inappropriate.

The authors' plea for a standardised approach to the analysis and reporting of cluster randomised trials is misguided. The framework that they describe has the patient as the principal unit of the experiment, with the correlation between patients in the same cluster having to be taken into account in the analysis. Following the recommendations in the editorial may, however, make investigators prey to the same errors that the authors are counselling them to guard against.

Although some trials fall naturally into the framework that the authors describe, others do not. It is not helpful in their own example of an educational intervention to implement a clinical guideline. There, the clinician (whose behaviour is the target of the intervention) is clearly the principal unit of the experiment. We are interested in the change in his or her behaviour as a result of the intervention, the average size of the change, and how the size varied between clinicians. Focusing on the estimation of these quantities of direct interest should lead to a sensible and interpretable analysis. Recognising that such estimates should be fit for purpose should lead to a sensible design. ${ }^{2}$

Adjusting the analysis on the basis of the intracluster correlation coefficient assumes the observed covariance structure to be the true structure, without taking into account 
measurement error. It is robust only where a reasonable estimate of variability at the clinician level is available. Thus to suggest that such methods are more efficient than aggregated analyses at the level at which the intervention is targeted is incorrect. The authors' quest for information on intracluster correlation coefficients is a search for an answer to the wrong problem. Thoughtless focus on correlation coefficients could lead to the use of values estimated in one study for calculations of sample size in quite a different area, which is probably worse than doing no such calculation at all.

The authors also suggest incorrectly that covariates at the patient level may not be examined in aggregated analyses. Generalised linear modelling provides the opportunity of specifying covariates at the patient level while analysing at the level at which the intervention is targeted.

Nick Freemantle Senior research fellow Medicines Evaluation Group, Centre for Health Economics, University of York, York YO10 5DD

John Wood Principal statistician

Statistical Sciences, SmithKline Beecham

Pharmaceuticals, Harlow, Essex CM19 5AW

1 Campbell MK, Grimshaw J. Cluster randomised trials: time for improvement. BMJ 1998;317:1171-2. (31 October.)

2 Wood J, Freemantle N. Choosing an appropriate unit of analysis in trials of interventions that attempt to influence practice.J Health Serv Res Policy (in press).

3 SAS/STAT Softward. Changes and enhancements through

release 6.12. Cary, NC: SAS/STAT Softward, 1997.

\section{Authors' reply}

EDITOR-We did not suggest that a standardised approach be adopted for the analysis of cluster trials. Our primary plea is that researchers account for the clustering in their data. Several methods are available to do this, and considerable debate surrounds the choice of method. We emphasised the use of hierarchical models; they allow all the information and variation at each level of the data to be explored while retaining the validity of the analysis. An aggregated approach may, however, be more appropriate for some analyses. Considerable debate also surrounds the choice of the unit of analysis. As Murray argues, however, this may be misplaced, and attention should rather be focused on the appropriate specification of the model for the analysis; the model selected should be well matched to the underlying structure of the data. ${ }^{1}$

We were surprised that Freemantle and Wood considered a standardised approach to the reporting of cluster randomised trials to be misguided. As Freemantle himself has indicated, implementation of the CONSORT guidelines for randomised trials should minimise the serious deficiencies in the design, analysis, and reporting of such trials. ${ }^{2}$ Extension of this statement to include the issues specific to cluster trials should yield similar benefits.

We also cannot agree with the suggestion that we should refrain from seeking further information on the intracluster correlation coefficient. Reliable estimates of this coefficient are required if robust calculations of sample size are to be made. Naturally, the gold standard approach is to measure the correlation coefficient directly within the study setting. However, the estimate of this coefficient, like other assumptions, is often informed by previous research or published reports. Because of the paucity of published information on the potential size of correlation coefficients in specific settings and on factors that might affect their magnitude, we (with other authors ${ }^{34}$ ) are promoting their routine publication. However, to suggest that using an external estimate, even if it is the best available, is worse than not calculating sample size at all is absurd. The adoption of such an approach would invalidate most calculations of sample size ever undertaken.

Marion K Campbell Senior statistician

Jeremy M Grimshaw Programme director

Health Services Research Unit, University of

Aberdeen, Aberdeen AB25 2ZD

m.k.campbell@abdn.ac.uk

1 Murray DM. The design and analysis of group randomised trials. Oxford: Oxford University Press, 1998. trials. Oxford: Oxford University Press, 1998. 2 Freemantle N, Mason JM, Haines A, Eccles MP. CONSORT: an important step toward ex
health care. Ann Intern Med 1997;127:81-3.

health care. Ann Intern Med 1997;127:81-3.

3 Donner A, Brown KS, Brasher P. A methodological review of non-therapeutic intervention trials employing cluste randomization, 1979-1989. Int J Epidemiol 1990;19: $795-800$

4 Ukoumunne OC, Gulliford MC, Chinn S, Sterne J, Burney P, Donner A. Evaluations of health care interventions a area and organisation level. In: Black N, Brazier J, Fitzpatrick R, Reeve B, eds. Health services research methods: a guide to best practice. London: BMJ Publishing, 1998.

\section{Areca nuts can have deleterious effects}

EDITOR-The United States nurses' study ${ }^{1}$ and the editorial that accompanies it report some health benefits of eating several helpings of nuts a week. These benefits cannot be generalised to all nuts commonly consumed, and it is important to specify which nuts confer them.

The areca nut (erroneously referred to as the betel nut) is chewed by over 200 million people worldwide-a tenth of the world's population. It is chewed either alone or as part of a quid known as "pan." This habit is practised commonly in central, southern, and southeast Asia and is now also emerging in Western countries. Recently new information on medical, biochemical, and psychological correlates of use of areca nuts have been reported. ${ }^{2}$ Several deleterious effects on oral and general health are now linked to use of the nuts. The consumption of areca has been strongly linked to the development of oral submucous fibrosis (a potentially malignant disorder of the oral cavity $^{3}$ ) and a high incidence of oral cancer in the Indian subcontinent and among Indian immigrants.

Consumption of areca has also been linked with cardiovascular disease, diabetes, and asthma. ${ }^{2}$ The mechanisms by which it may induce cardiovascular disease are not clear. A recent study in a Bangladeshi population in east London found raised homocysteine and reduced folate concentrations in 170 healthy regular chewers. ${ }^{4}$ High serum homocysteine concentrations have been associated with an increased risk of acute ischaemic heart disease. Another possible mechanism involves the copper-dependent enzyme lysyl oxidase, which has a role in the cross linking of collagen and atherogenesis in the major vessels. Areca contains a high level of copper (302 (SD 92) nmol/g (range 205-535)) compared with other nut based snacks (range 22-173 nmol/g) and upregulates lysyl oxidase activity.

We have recently described an areca dependency syndrome in a group of Indian (Gujarati) immigrants living in west London who were addicted to areca products. ${ }^{2}$ As the American study has shown, eating nuts may be a safe and healthy habit. However, recommendations encouraging frequent consumption should specify safe nuts and consider deleterious effects of some nuts such as areca.

Chetan Trivedy Research fellow

Saman Warnakulasuriya Senior lecturer in oral medicine

s.warne@kcl.ac.uk

Timothy J Peters Professor of clinical biochemistry

King's College Hospital, London SE5 9RW

1 Hu FB, Stampfer MJ, Manson JE, Rimm EB, Colditz GA, Rosner BA, et al. Frequent nut consumption and risk of coronary heart disease in women: prospective cohot study. BMJ 1998;317:1341-5. (14 November)

2 Winstock AR, Trivedy CR, Warnakulasuriya KAAS, Peters

TJ A Cependency syndrome related to areca nut use Peters 1.. A dependency sydrome related to areca nut use: some in the Gujo in the Gujarat con 3 Warnakulasuriya KAAS, Trivedy C, Maher R, Johnson NW. Aetiology of oral submucous fibrosis. Oral Dis

4 Obeid OA, Mannan N, Perry G, Iles RA, Boucher BJ Homocysteine and folate in healthy east London Bangladeshis. Lancet 1998;352:1829-30.

5 Trivedy C, Baldwin D, Warnakulasuriya KAAS, Johnson NW, Peters TJ. Copper content in areca catechu (betel nut) products and oral submucous fibrosis. Lancet 1997;340:1447.

\section{Fractures of the thoracolumbar spine in major trauma patients}

\section{ATLS manual does recognise importance of distracting injuries}

EdiTor-Meek is right to highlight the potential danger of missing fractures of the thoracolumbar spine in patients with trauma if the need for $x$ ray investigations is based purely on the clinical examination. But he is wrong to say that the Advanced Trauma Life Support Manual for Physicians "does not recognise the importance of a distracting injury in masking the symptoms and signs of spinal fracture."

I believe that the quotation he gave was from the introductory section of the chapter on spinal trauma. The following quotes are from the same chapter." "Any patient with an altered level of consciousness or cognitive dysfunction (GCS <15), multisystem injuries, ... requires spinal protection until AP [anteroposterior] and lateral [thoracolumbar] spine $x$-rays are obtained to exclude any injury." "In the secondary survey ... thoracolumbar spine films may be obtained $\ldots$ if the mechanism of injury suggests the possibility of spinal injury." "Other injuries may mask the physical findings of spinal injuries, which may go unsuspected unless the doctor obtains the appropriate x-rays." 
The work of Cooper et al quoted in the article is also referenced at the end of the relevant chapter in the manual.

Ray McGlone Instructor in advanced trauma life support

Royal Lancaster Infirmary, Lancaster LA1 4RP Ray.McGlone@laht.nwest.nhs.uk

1 Meek S. Lesson of the Week. Fractures of the thoracolumbar spine in major trauma patients. BMJ 1998;317:1442-3. (21 November.)

2 American College of Surgeons Committee on Trauma Advanced trauma life support manual for physicians. Chicago: Adwanced tran. 1997.

3 Cooper C, Dunham CM, Rodriguez A. Falls and major injuries are risk factors for thoracolumbar fractures: cognitive impairment and multiple injuries impede the detection of back pain and tenderness. J Trauma 1995;38: $692-6$

\section{It happened to me!}

EDITOR-Meek's paper on fractures of the thoracolumbar spine in major trauma patients reminded me of my own experiences as a victim of major trauma. ${ }^{1}$ In April 1998 I was riding my motorcycle to Devon on the M5 when I (and six cars) was struck from behind by a 24.4 tonne lorry. Whiplash back and forward occurred several times as I was knocked into the car in front. I was not struck on the head, and I remained fully conscious and alert throughout. However, I suffered a fracture of my left femur, a compound fracture of the left tibia and fibula close to the knee joint, and an open stab wound to the left knee joint. I had pain around the right lower ribs, but at the scene and in casualty I did not have any pain in the back.

I was taken to theatre: the femoral fracture was fixed with an intramedullary nail, and a temporary external fixator was applied to the fracture of the tibia and fibula. An epidural was inserted for postoperative pain relief. Over the next three days I developed increasing pain in the area of the lumbar spine that eventually became agonising and was not relieved by increasing the epidural analgesia. After further surgery, mobilisation was ordered. Finally, after I was crying out in pain, a routine (non-urgent) $x$ ray examination of my lumbar spine was ordered, which was not performed until the next day (five days after the accident); this showed a wedge fracture of L1. Only after the $x$ ray film was obtained was my spine examined. There were no neurological problems after this fracture, which has healed well, as have the other fractures.

I was certainly at risk by Meek's definitions, because I was riding a motorcycle and had other, distracting painful injuries. Perhaps, though, a medical background should be added to his list of risk factors-although I recognised the symptoms of spinal fracture, I was reluctant to make a fuss or be an awkward patient so did not complain nearly loudly or long enough.

Sarah Walters Senior clinical lecturer in public health and epidemiology

University of Birmingham, Birmingham B15 2TT s.walters@bham.ac.uk

1 Meek S. Lesson of the Week. Fractures of the thoracolumbar spine in major trauma patients. BMJ 1998;317:1442-3. (21 November.)

\section{Evidence does not exist that dyspepsia heralds gastric cancer in its earliest stage}

EDITOR-The editorial claiming that proton pump inhibitors may mask early gastric cancer recommends that "dyspeptic patients over 45 should undergo endoscopy before these drugs are started."1 The authors argue that this policy is justified by the improved curability of gastric cancer diagnosed at an early stage. They quote the studies by Hallissey et al and Fielding et al, which show an increased proportion of gastric cancers diagnosed at an early stage when all dyspeptic patients aged over 40 are invited to undergo gastroscopy. ${ }^{23}$ No control group of otherwise matched non-dyspeptic patients was studied. These results therefore do little more than show that as a population undergoes increased gastroscopy so gastric cancer presents earlier, rather than that dyspepsia is a useful symptom heralding gastric cancer in its earliest stage.

There may be good reasons for carrying out endoscopy for all patients over 45 with onset of dyspepsia before treating them with an acid suppressant; evidence does not yet exist, however, to show that the ability to diagnose gastric cancer early is one of them.

Thomas S Low-Beer Consultant physician 38 Weoley Park Road, Birmingham B29 6RB t.s.low-beer@bham.ac.uk

1 Griffin SM, Raimes SA. Proton pump inhibitors may mask early gastric cancer. BMJ 1998;317:1607-8. (12 December.) 2 Hallissey MT, Allum WH, Jewkes AJ, Ellis DJ, Fielding JWL Early detection of gastric cancer. BMJ 1990;301:513-5.

3 Fielding JWL, Ellis DJ, Jones BG, Paterson J, Powell DJ, Waterhouse JAH, et al. Natural history of "early" gastric Waterhouse JAH, et al. Natural history of "early" gastric
cancer: results of a 10-year regional survey. BMJ 1980;281:965-7.

\section{Adjusting for multiple testing in studies is less important than other concerns}

EDITOR-In a paper in the American Journal of Public Health Aickin stated that "there is substantial debate ... concerning when (if ever) adjustment for multiple testing is warranted." I am glad that he has joined the debate in the $B M J$ over Bonferroni adjustments but find his arguments unconvincing. ${ }^{2}$ Yes, "researchers who adjust $P$ values almost always present them for their individual hypotheses," as he says. This is why they should not worry about unrelated tests and renounce a statistical technique that focuses on the largely irrelevant universal null hypothesis.

Statistical tests were developed for repeated testing, such as industrial quality control. The $\alpha$ and $\beta$ error rates are valid in the long run, as asymptotic averages. Hence multiple testing is no violation of test theory, it is a prerequisite. Industrialists know that over time they will reject a proportion of good lots $(\alpha)$ and market a proportion of bad lots $(\beta)$ in error; researchers know that in their career they will reject a proportion of true null hypotheses $(\alpha)$ and miss a proportion of true alternative hypotheses (ß). These proportions do not vary with the number of tests.

Dredging data is a smart and cost effective way of doing research. "Dredge your data and [do] not tell" are Aickin's words; my advice was to "describe what was done." " Besides, Bonferroni adjustments make no distinction between data dredging and multiple planned tests.

What tests to include in the adjustment is a serious issue since it will determine whether a result will be "significant" or not. Aickin does not seem to have an answer; nor does anyone else. Pushing a reasoning to the point of absurdity is a rhetorical device to show that the reasoning does not hold.

The only advantage of Holm adjustments over Bonferroni adjustments is that they inflate $\beta$ errors less, but the procedure is complex. ${ }^{1}$ I doubt that Holm-adjusted $\mathrm{P}$ values are understandable to anyone but a few statisticians. As for the American Journal of Public Health-its instructions for authors in the December 1998 issue include no statement about multiple test adjustments, and the three first articles contain respectively 70,110 , and 114 tests, in tables only, without any multiple test adjustment.

I am baffled that "whether a given study should be statistically analysed at all" should concern anyone. We should worry whether to do the study in the first place and, when it is done, how best to interpret the data. Multiple test adjustments help with neither of these.

Thomas V Perneger Medical epidemiologist Institute of Social and Preventive Medicine, University of Geneva, CMU, CH-1211 Geneva 4, Switzerland

pernegr@cmu.unige.ch

1 Aickin M, Gensler H. Adjusting for multiple testing when reporting research results: the Bonferroni vs Holm methods. Am J Public Health 1996;86:726-8.

2 Aickin M. Other method for adjustment of multiple testing exists. BMJ 1999;318:127. (9 January.)

3 Perneger TV. What's wrong with Bonferroni adjustments. BMJ 1998;316:1236-8.

\section{Cited studies did not show relation between maternal anxiety and birth weight}

Editor-Teixeira et $\mathrm{al}^{1}$ state that "some studies have shown that babies of stressed or anxious mothers have a significantly lower than average birth weight for gestational age and tend to be born early" and then reference four papers, one of which is mine. ${ }^{2}$ The St George's birthweight study was a large prospective study of pregnant women which measured anxiety and depression throughout pregnancy. We found no association between anxiety and depression and either prematurity ${ }^{2}$ or low birth weight. ${ }^{3}$ Nor was any association found with life events as measured by Paykel's interview for recent life events.

Interestingly, having demonstrated that high anxiety levels are linked to an increased uterine artery resistance index, Teixeira et al note that the index is predictive of intrauterine growth retardation. Thus it is paradoxical that one of the largest cohort studies of 
anxiety, depression, and stress in pregnancy, which was also referenced, found no association between any of the above and intrauterine growth retardation. ${ }^{4}$ Although the results were based on a single psychosocial assessment at 26 weeks, like the St George's study, it found no relation between anxiety and depression and prematurity or low birth weight. There was, however, an association between increasing levels of stress and prematurity and low birth weight.

Finally, the Danish study of 5873 women that was cited found that women who had one or more life events that they perceived as being highly stressful had a risk of preterm delivery 1.76 times greater than those without stressful life events. ${ }^{5}$ This sounds impressive but equates to a decrease in length of gestation of 1.06 days, which is of no clinical importance.

The findings of Teixeira et al are interesting and warrant further study. However, caution has to be exercised in interpreting large epidemiological studies that confine psychological assessments of pregnant women to the beginning of the last trimester. Women at this stage may already be aware, through ultrasound assessments, fundal measurements, or blood pressure problems, that there is a problem with their pregnancy, which may induce stress and anxiety.

Michael Perkin Paediatric specialist registrar Mayday University Hospital, Croydon CR7 7YE

1 Teixeira JMA, Fisk NM, Glover V. Association between maternal anxiety in pregnancy and increased uterine artery resistance index: cohort based study. BMJ 1999.318:153-7. (16 January)

2 Perkin MP, Bland JN, Peacock JL, Anderson HR. The effect of anxiety and depression during pregnancy on obstetric of anxiety and depression during pregnancy on obst
complications. Br J Obstet Gynaecol 1993;100:629-34.

3 Brooke OG, Anderson HR, Bland JM, Peacock JL, Stewart CM. Effects on birthweight of smoking, alcohol, caffeine socioeconomic factors, and psychosocial stress. $B M J$ 1989;298:795-801.

4 Copper RL, Goldenberg RJ, Das A, Elder N, Swain M, Norman G, et al. The preterm prediction study: maternal stress is associated with spontaneous preterm birth at less than 35 weeks gestation. Am J Obstet Gynecol $1996 ; 175: 1286-92$

5 Hedegaard M, Henriksen TB, Secher NJ, Hatch MC, Sabroe S. Do stressful life events affect duration of gestation and risk of preterm delivery? Epidemiolog 1996;7:339-45.

\section{Inclusive questions are needed when taking a sexual history}

EDitor-I welcome the $\mathrm{ABC}$ of Sexual Health but found the article on taking a sexual history to be limited.

Creating the best environment for patients to feel comfortable when discussing issues of sex and sexuality starts before the patient enters the doctor's office. Intake forms that ask if the patient is married or single and health information pamphlets that do not include information for gay and lesbian couples reinforce the real and perceived homophobia of the medical system, making the hurdle of disclosure to the provider formidable. The article clearly assumed that patients are heterosexual, as most doctors do: a psychiatrist colleague recently told me that she thought she had no gay or lesbian patients. If the doctor's first concern is to determine the patient's marital status or to rule out marital dysfunction, as suggested in the article, then a gay, lesbian, or bisexual patient is immediately alienated.

The use of more inclusive questions such as "Who are the most important people in your life?" and, more specifically, "Are you sexually active with men, women, or both?" will allow the patient to answer honestly and validate his or her relationships. The use of such questions will send a clear, normalising message and tell the patient that this is a safe place in a largely hostile health system.

Peter Meacher Family physician

Department of Family Medicine, Montefiore Medical Center, 3544 Jerome Avenue, Bronx, NY 10467 , USA

kenandpete@aol.com

Competing interests: Peter Meacher is codirector of the Bronx Lesbian and Gay Healthcare Consortium, an activist group in the Bronx.

1 Tomlinson J. ABC of sexual health: Taking a sexual history. BMJ 1998;317:1573-6. (5 December.)

\section{Drugs for epilepsy have teratogenic risks}

EDITOR-We would like to draw attention to the fact that no anticonvulsant has been shown to be without risk to the fetus in pregnancy. ${ }^{1}$ Associations with neural tube defects and facial clefts are well recognised, but congenital abnormalities alone are a crude indicator of teratogenicity. Of increasing concern is the risk of intellectual impairment, which is frequently only apparent in later childhood. Several studies that include long term follow up are currently under way.

We recognise that anticonvulsant treatment during pregnancy is unavoidable for many women, for whom attempts should be made to achieve control with the fewest agents and lowest dose possible. Nevertheless, we also recognise that many women of childbearing age, despite being seizure free for several years, continue to take anticonvulsants rather than risk losing their driving licence should a seizure occur when treatment is withdrawn. These women are unable to make informed decisions unless they are fully aware of the teratogenic risks of their treatment.

More subtle effects of exposure to anticonvulsants in utero are increasingly recognised, frequently by developmental paediatricians and clinical geneticists. ${ }^{23}$ The experience with newer anticonvulsants is limited. ${ }^{4}$ Failure to appreciate the risk of neurological impairment to the fetus by clinicians prescribing anticonvulsants and providing preconceptional advice can mislead parents. Indeed, we are aware of several instances where this omission has resulted in litigation.

Elisabeth M Rosser Consultant

Louise C Wilson Consultant

Unit for Clinical Genetics, Institute of Child Health, London WC1N 1EH

L.Wilson@ich.ucl.ac.uk
1 Feely M. Drug treatment of epilepsy. BMJ 1999;318:106-9. (9 January.)

2 Clayton-Smith J, Donnai D. Fetal valproate syndrome. JMed Genet 1995;32:724-7.

3 Ornoy A, Cohen E. Outcome of children born to epileptic mothers treated with carbamazepine during pregnancy. Arch Dis Child 1996;75:517-20.

4 Morrell MJ. The new antiepileptic drugs and women: efficacy, reproductive health, pregnancy and fetal outcome. Epilepsia 1996;37(suppl 6):S34-44.

\section{Alcohol intake and cancer of the upper digestive tract}

\section{Pattern of risk in Italy is different from that in Denmark}

EDITOR-A Danish study of 156 subjects with upper digestive tract cancers showed that wine drinkers may be at a lower risk than drinkers with a similar intake of beer or spirits. ${ }^{1}$ Wine is the most common alcoholic beverage in Italy, accounting for over $80 \%$ of alcohol intake. ${ }^{2}$ We investigated the separate and combined effect of wine drinking in a large dataset. ${ }^{3}$

Data were collected between 1984 and 1993 in Greater Milan and the province of Pordenone, Northern Italy, on 547 histologically confirmed incident cases of cancer of the oral cavity and pharynx (466 men, 81 women; age 22-74 (median 57)) and 412 cases of cancer of the oesophagus (345 men, 67 women; age 26-74 (median 60)). Controls were 2375 subjects (1797 men, 578 women; age 25-74 (median 56)) admitted to the same network of hospitals with acute non-neoplastic conditions unrelated to alcohol or tobacco consumption. Of these, 570 were admitted for trauma, 593 for non-traumatic orthopaedic conditions, 475 for acute surgical diseases, 428 for eye diseases, and 309 for miscellaneous other illnesses. Trained interviewers questioned cases and controls, using a structured questionnaire; questions on the days per week that each type of alcoholic beverage (wine, beer, and spirits) was consumed and the average number of drinks per day were included.

The table gives the distribution of cases of oral and pharyngeal and oesophageal cancer and of the comparison group according to consumption of various alcoholic beverages. When non-drinkers and moderate drinkers $(<3$ drinks a day) were used as the comparison group, the odds ratios of oral and pharyngeal cancer were 4.95 for very heavy ( $\geqslant 10$ drinks per day) wine drinkers and 4.13 for very heavy wine, beer, and spirit drinkers. Corresponding findings for oesophageal cancer were 7.53 and 5.52. The odds ratios for beer or spirit drinkers only were 0.9 (95\% confidence interval 0.3 to 2.4) for cancers of the oral cavity ( 7 cases, 47 controls) and 1.5 (0.6 to 3.9) for oesophageal cancer (7 cases, 47 controls). These results were consistent across separate diagnostic conditions in controls.

This pattern of risk according to type of alcoholic beverage is different from that reported in the Danish study. ${ }^{1}$ Taken together, these data lead us to conclude that 
Distribution of 547 cases of oral and pharyngeal cancer, 412 cases of oesophageal cancer, and 2375 controls, and corresponding multivariate odds ratios * and $95 \%$ confidence intervals, according to total number of drinks per week of wine only and wine, beer, or spirits, Italy, 1984-93

\begin{tabular}{|c|c|c|c|c|c|c|c|c|}
\hline \multirow[b]{3}{*}{ No of drinks/week } & \multicolumn{4}{|c|}{ Oral cavity and pharynx } & \multicolumn{4}{|c|}{ Oesophagus } \\
\hline & \multicolumn{2}{|c|}{ Wine only } & \multicolumn{2}{|c|}{ Wine and other } & \multicolumn{2}{|c|}{ Wine only } & \multicolumn{2}{|c|}{ Wine and other } \\
\hline & $\begin{array}{l}\text { Cases of } \\
\text { cancer: } \\
\text { controls }\end{array}$ & Odds ratio $(95 \% \mathrm{CI})$ & $\begin{array}{l}\text { Cases of } \\
\text { cancer: } \\
\text { controls }\end{array}$ & Odds ratio $(95 \% \mathrm{Cl})$ & $\begin{array}{l}\text { Cases of } \\
\text { cancer: } \\
\text { controls }\end{array}$ & Odds ratio $(95 \% \mathrm{CI})$ & $\begin{array}{l}\text { Cases of } \\
\text { cancer: } \\
\text { controls }\end{array}$ & Odds ratio $(95 \% \mathrm{Cl})$ \\
\hline Non-drinkers & $37: 365 \dagger$ & \multirow{2}{*}{$1 \dagger$} & $37: 365^{*}$ & \multirow{2}{*}{$1 \dagger$} & $41: 365^{\star}$ & \multirow{2}{*}{$1 \dagger$} & $41: 365^{*}$ & \multirow{2}{*}{$1 \dagger$} \\
\hline$<21$ & $47: 541$ & & $9: 175$ & & $46: 541$ & & $16: 175$ & \\
\hline $21-41$ & $59: 377$ & $1.49(1.00$ to 2.23$)$ & $30: 293$ & $0.93(0.54$ to 1.62$)$ & $52: 377$ & 1.60 (1.06 to 2.40$)$ & $39: 293$ & 1.45 (0.88 to 2.39$)$ \\
\hline $42-69$ & 102:155 & 4.94 (3.26 to 7.47$)$ & $85: 258$ & 2.33 (1.40 to 3.88$)$ & $82: 155$ & 5.81 (3.81 to 8.86$)$ & $62: 258$ & 2.76 (1.68 to 4.53 ) \\
\hline$\geqslant 70$ & $23: 18$ & 4.95 (2.32 to 10.56$)$ & $155: 190$ & 4.13 (2.45 to 6.97$)$ & $7: 18$ & 7.53 (2.63 to 21.53 ) & $65: 190$ & 5.52 (3.16 to 9.65$)$ \\
\hline
\end{tabular}

*Estimates from multiple logistic regression equation including centre, age, sex, education, social class, and smoking habit. The sum of strata do not add up to the total because a few values are missing. †Reference category is non-drinkers and those drinking <21 drinks/week combined.

ethanol is the main component of alcoholic beverages that determines the risk of cancer and that the most frequently consumed beverage in each area tends to be the one with the highest risk. ${ }^{45}$ Wine consumption is clearly strongly related to cancers of the upper digestive tract in individuals and populations with heavy consumption.

Carlo La Vecchia Associate professor of epidemiology Istituto di Statistica Medica e Biometria, Università di Milano, 20133 Milan, Italy

Silvia Franceschi Consultant epidemiologist

Adriano Favero Staff scientist

Renato Talamini Registrar

Centro Regionale Oncologico, 33081 Aviano PN,

Italy

Eva Negri Head, unit of epidemiological methods Istituto di Ricerche Farmacologiche, Mario Negri, 20157 Milan, Italy

1 Grønbæk M, Becker U, Johansen D, Tønnesen H, Jensen G, Sørensen TI. A population based cohort study of the association between alcohol intake and cancer of the upper digestive tract. BMJ 1998;317:844-8. (26 September.)

2 La Vecchia C. Alcohol in the Mediterranean diet 2 La Vecchia C. Alcohol in the Mediterranean diet. 3 Assessing risks and benefits. Eur J Cancer Prev 1995;4:3-5. Type of alcoholic beverage and cancer of the oral cavity, pharynx and oesophagus in an Italian area with high wine consumption. Int J Cancer 1990;46:1017-20

4 Doll R, Forman D, La Vecchia C, Woutersen R. Alcoholic beverages and cancers of the digestive tract and larynx. In: Verschuren PM, ed. Health issues related to alcohol consumption. Washington: International Life Sciences Institute, 1993:126-66.

5 International Agency for Research on Cancer. Alcohol drinking. Lyons: IARC, 1988. (IARC monographs on the evaluation of carcinogenic risks in humans volume 44.)

\section{Confounding in such studies is important}

EDITOR-Grønbæk et al concluded that moderate consumption of wine does not increase the risk of cancer of the upper digestive tract whereas a similar intake of beer or spirits does. ${ }^{1}$ This is a potentially important finding, at least for those of us who mostly drink wine. But several issues concerning confounding warrant some discussion.

Firstly, there seemed to be fewer heavy drinkers ( $>21$ drinks/week) in the group in which wine constituted $>30 \%$ of total alcohol intake than in the group in whom it constituted $0 \%$ of the intake $(10.2 \% v 31.2 \%$, from data in table 2). It has been documented that there is probably little increase in risk of oesophageal cancer below an intake of $200 \mathrm{~g}$ /week (16.7 drinks from Grønbæk et al's definition). ${ }^{2}$ It would have been useful if the authors had subdivided the $>21$ drinks/ week category to examine the risks associated with higher intake so that residual confounding could be excluded, although such an attempt may be hampered by small numbers.
Another source of potential residual confounding is the amount of tobacco smoked. Again, to adjust properly for any confounding effects arising from smoking one would like to see finer divisions of intake than those reported in the paper $(1-19 \mathrm{~g} /$ day and $20 \mathrm{~g} /$ day).

Finally, the authors mentioned the absence of data on diet. It has been shown consistently that eating fresh fruit and vegetables is strongly protective against oesophageal cancer. ${ }^{3}$ In the West Midlands a recent survey on lifestyles showed that wine drinkers tended to have a better diet than those who drank beer or spirits (unpublished data). If this was also the case in Denmark then it could explain at least part of the difference observed. The authors' case would be stronger if they can show that such associations do not exist in Denmark.

On the whole, we would agree with the editorial accompanying the paper that there is "still no clear evidence to link specific beverages to specific cancers."

K K Cheng Professor of epidemiology

C Cummins Lecturer

R Maric Research fellow

Department of Public Health and Epidemiology, University of Birmingham, Birmingham B15 2TT K.K.Cheng@bham.ac.uk

1 Grønbæk M, Becker U,Johansen D, Tønnesen H, Jensen G, Sørensen TIA. Population based cohort study of the association between alcohol intake and cancer of the uppe digestive tract. BMJ 1998;317:844-7. (26 September.)

2 Cheng KK, Duffy SW, Day NE, Lam TH, Chung SF, Badrinath P. Stopping drinking and risk of oesophageal cancer. BMJ 1995;310:1094-7.

3 Cheng KK, Day NE. Nutrition and esophageal cancer. Cancer Causes Control 1996;7:33-40.

4 Sabroe S. Alcohol and cancer. BMJ 1998;317:827. (26 September.)

\section{Such studies should be done in non-smokers}

EDitoR-Grønbæk et al's study is a further example of a large epidemiological study in which smokers have been included even though smoking was likely to be a risk factor for the disease under study. ${ }^{1}$ Statistical manipulation was then used to correct for the effects of smoking. But how reliable are these corrections, and how much faith should be put in the answers obtained with regard to the specific question of alcohol consumption causing cancer? Given that corrections for relatively straightforward data are often only approximate, the development of cancer is unlikely to be accurately corrected for, particularly when smoking habit is only broadly classified.

The term "correction for smoking" is ambiguous. In some studies authors have clearly analysed out the effects of smoking and extrapolated back, in order to predict values for non-smokers. The present authors seem to have corrected to a standard value for smoking, probably the median of their categories. If this interpretation is correct then their graphs and tables show the morbidity standardised for a population who had formerly smoked for at least five years.

The authors suggest that smoking was not the main influence on morbidity since the level of cancer in the heavy smokers (risk 7.1) was lower than that in the heavy drinkers (risk 11.7). However, their figure 1 indicates that this risk in heavy smokers was in fact higher than that for all but one of the alcohol consumption categories, which implies that a large proportion of the morbidity may still have occurred in the smokers. They also point out that heavy smoking and heavy drinking tended to go together, which makes accurate correction even harder.

Many non-smokers are treated with drugs to reduce their cholesterol concentration or blood pressure, largely on the evidence of studies that have included smokers and in which smokers have contributed most of the morbidity. The justification for treating non-smokers is generally based on an extrapolation that finds a small residue of morbidity even after smoking has been corrected for. If those corrections overestimate the true risk to non-smokers then these patients might be taking long term medication that may not benefit them since they were not at risk in the first place. We know that smoking is a risk factor for most respiratory and cardiovascular disease as well as for most cancers and some gastrointestinal disorders. Should we not perform epidemiological studies specifically on non-smokers or, at the very least, request authors to provide summary tables of their main findings specifically for the non-smoking subset of their population?

Vaughan Reed Freelance statistician

4 Inverlea Court, Mickleton, Gloucestershire GL55 6TZ

101373.341@compuserve.com

1 Grønbæk M, Becker U, Johansen D, Tønnesen H, Jensen G, Sørensen TIA. Population based cohort study of the association between alcohol intake and cancer of the upper digestive tract. BMJ 1998;317:844-7. (26 September.) 
Treating upper digestive tract cancers as a single entity may be misleading

EDITOR-Grønbæk et al reported that the type of alcohol consumed may be important in determining the risk of cancer of the upper digestive tract in their population based study in Copenhagen. ${ }^{1}$ In this large epidemiological study details about the alcohol intake and the particular type of alcoholic beverage were obtained by questionnaire. Patients with cancer of the upper digestive tract were then identified from the Danish cancer registry. This registry subdivides oral cavity, pharyngeal, and oesophageal cancers, but the authors make no comment about whether their results applied to all cancers of the upper digestive tract uniformly or not. This information may be important considering the different pathogenesis of these cancers.

Oesophageal cancers, in particular, are made up of two main groups with very different pathogenesis. Squamous carcinoma is declining in incidence in the Western world and is strongly associated with alcohol and tobacco intake, whereas adenocarcinoma (which is associated with the premalignant condition Barrett's oesophagus) is rapidly increasing in incidence and does not appear to be so strongly associated with smoking and alcohol, although further information is needed. ${ }^{2}$ We appreciate that in the Danish study it would have been difficult for the authors to obtain information on the types of oesophageal cancer, since the cancer registry does not separate the histopathological subtypes. In a Medline search $(1995-8)$ on the relation between oesophageal cancer and alcohol only five of 12 papers specified which histopathological subtype they were referring to.

It is time that cancer registries classified oeosphageal adenocarcinoma separately from squamous carcinoma so that we can gain meaningful information about the epidemiology of these important conditions.

Rebecca Fitzgerald Lecturer in gastroenterology St Bartholomew's and the Roval London School of Medicine and Dentistry, London E1 2AD rcfitzgerald@mds.qmw.ac.uk>

Christine Caygill Epidemiologist

National Barrett's Oesophagus Registry, Wexham Park Hospital, Slough, Berkshire SL2 4HL

1 Grønbæk M, Becker U, Johansen D, Tønnesen H, Jensen G, Sørensen TIA. Population based cohort study of the association between alcohol intake and cancer of the upper digestive tract. BMJ 1998;317:844-7. (26 September.)

2 Vaughan TL, Davis S, Kristal A, Thomas DB. Obesity, alcohol and tobacco risk for cancers of the esophagus and gastric cardia: adenocarcinoma vs squamous cell carcinoma Cancer Epidemiol, Biomarkers and Prev 1995;4: 85-92.

\section{Authors' reply}

EDIToR-The large number of cases in La Vecchia et al's case-control study enables them to present a detailed analysis of the effect of wine only and wine together with other types of drinks. Their study shows what ours cannot-namely, that even with wine there is an increased risk of the cancers. As Cheng et al point out, our study was hampered by a smaller number of cases in the heavy drinking categories. Unfortunately, La Vecchia et al's study does not provide an estimate for non-drinkers and does not distinguish the effect of drinking wine from the effect of drinking beer and spirits.

Both Cheng et al and Reed are concerned about the possible confounding effect of smoking, which we controlled for quite thoroughly. In one analysis (reported in the paper) we controlled for smoking by taking into account differences in the prevalence of smoking among individuals at different levels of wine percentages and of total alcohol intake in the Cox regression models. In another model (not reported) we took into account the number of pack-years and inhalation; this yielded the same results as those in the paper. The number of cases did not allow stratified analyses of smokers and non-smokers. However, the aim of the study was not to assess smoking or alcohol intake as risk factors for cancer of the upper digestive tract (this has been extensively studied) but to search for potential differences in the effects of the three types of alcohol. Unless the effect of smoking and type of alcoholic beverages interact, the need to estimate risk among smokers and non-smokers is less prominent.

As Cheng et al point out, a few studies have shown a protective effect of fruit and vegetable intake on oesophageal cancer. To be a confounder in the present analysis, however, the effects of intake of fruit and vegetables and its association with wine intake would have to be unexpectedly strong to explain our findings.

If we had had a larger number of cases we would have been able to distinguish between these types of cancer and even the histopathological subtypes, as suggested by Fitzgerald and Caygill. If we misclassified some of the cases we would expect this to have reduced the differences in the effects of beer, wine, and spirits.

Morten Grønbæk Senior research fellow Thorkild I A Sørensen Professor

Copenhagen Centre of Prospective Population Studies, Danish Epidemiology Science Centre at the Institute of Preventive Medicine, Copenhagen University Hospital, Kommunehospitalet, DK-1399 Copenhagen K, Denmark mg@ipm.hosp.dk

\section{Meeting the healthcare needs of refugees and asylum seekers}

EDITOR-Kent has around 4000 asylum seekers, many of whom are not registered with a general practitioner. The local medical committee recently wrote to all the members of parliament (MPs) in Kent seeking separate central funding to provide adequate services for refugees and asylum seekers. The committee was concerned that an effective service was unlikely to be provided unless funds were separately identified and also that funds for general medical services would be used to provide a service that takes money from the population as a whole. The response from local MPs was overwhelmingly supportive, but Frank Dobson ignored the plea for a properly funded service, stating that the policy of dispersion and the proposed policy of fast tracking refugees would solve the problems.

We remain sceptical. Currently, East Kent has a large number of refugees and asylum seekers and is popular with London boroughs for its cheap and available accommodation and its proximity to London. In addition, landlords with vacant rooms in the area are encouraging London boroughs to lodge refugees in their rooms.

In consultation with the local medical committee and with the support of local general practitioners the health authority has instigated a scheme to provide a service directed at the specific needs of refugees and asylum seekers. It consists of one and a half whole time equivalent general practitioners, three nurses, and reception staff in three surgeries (Dover, Folkestone, and Thanet). All staff have appropriate skills and access to translating and other services. The service should lead to the registration of many more refugees and asylum seekers with a general practitioner and to an understanding of the use of services by these patients so that they can in time be properly integrated into the NHS.

The scheme is funded by the NHS modernisation fund, and the cost of nursing is met by an allocation from the health authority's service and financial framework, with agreement that any overspend will come directly from cash limited funds for general medical services. In the future the local medical committee will need to consult with primary care groups, five in the case of East Kent. We wonder how each will respond as refugees and asylum seekers are currently concentrated in comparatively small and deprived areas.

Although general practitioners in Kent might support the government's aim of dispersal, the reality is likely to be much more difficult to achieve than a properly funded initiative that addresses the problems faced by refugees and asylum seekers and the health and social services that are trying to support them.

David Barr Clerk david.barr@virgin.net

J B Ashton Medical secretary

Kent Local Medical Committee, Suite 1, First Floor, Tenacre Court, Herrietsham, Kent ME10 1AH

1 Home Office. Fairer, faster, and firmer-a modern approach to immigration and asylum. London: Stationery Office, 1998. (Cm 4018.)

\section{Rapid responses} $e \mathrm{BM}$

Rapid responses submitted directly to our website are available on www.bmj.com 